\title{
Antimicrobial resistance in Neisseria gonorrhoeae and Treponema pallidum: evolution, therapeutic challenges and the need to strengthen global surveillance
}

\author{
David A Lewis, ${ }^{1,2,3,4}$ Sheila A Lukehart ${ }^{5}$
}

${ }^{1}$ Sexually Transmitted Infections Reference Centre, National Institute for Communicable Diseases, National Health Laboratory Service, Johannesburg, South Africa ${ }^{2}$ Department of Internal Medicine, Faculty of Health Sciences, University of the Witwatersrand, Johannesburg, South Africa

${ }^{3}$ Division of Microbiology, University of Cape Town, Cape Town, South Africa

${ }^{4}$ London School of Hygiene and Tropical Medicine, London, UK ${ }^{5}$ Departments of Medicine and Global Health, University of Washington, Seattle,

Washington, USA

\section{Correspondence to} Professor David Lewis, STI Reference Centre, National Institute for Communicable Diseases, Private Bag X4, Sandringham 2131, South Africa; davidl@nicd.ac.za

Accepted 18 May 2011

This paper is freely available online under the BMJ Journals unlocked scheme, see http://sti. bmj.com/site/about/unlocked. xhtml

\section{INTRODUCTION}

The emergence of drug resistance among bacterial, viral and protozoan sexually transmitted infections (STI) in recent years threatens to undermine global STI control programmes. While this review will focus on microbiological resistance determinants for two important bacterial STI pathogens, namely Neisseria gonorrhoeae and Treponema pallidum, it is important to appreciate that a number of nonmicrobiological determinants may also directly influence both the emergence and transmission of antimicrobial resistant STI pathogens (table 1). This short paper describes the historical development of antibiotic resistance in $N$ gonorrhoeae and $T$ pallidum, outlines the challenges of identifying and treating these resistant infections, and highlights the requirement for the strengthening of global microbiological surveillance programmes for STI.

\section{N GONORRHOEAE INFECTION}

Gonorrhoea treatment in the pre-cephalosporin era The gonococcus is characterised by a remarkable ability to develop and acquire antibiotic resistance mechanisms (table 2). ${ }^{1}$ Following the rapid demise of sulphonamides in treating gonorrhoea in the early 1940s, penicillins became the mainstay of global therapy for almost 40 years, initially at very low dosage and subsequently given at higher doses with probenecid. Tetracyclines or erythromycin were used during this period for the management of penicillin allergic patients and sometimes for cases of chromosomally mediated penicillin-resistant $N$ gonorrhoeae infection. The global spread of highlevel plasmid-mediated penicillin and tetracycline resistance among $N$ gonorrhoeae isolates in the 1980s effectively sealed the fate of these antibiotics in terms of gonorrhoea treatment. ${ }^{1}$

Spectinomycin provided a temporary solution to the problem of penicillinase-producing $N$ gonorrhoeae but resistance rapidly developed with firstline use. ${ }^{2}$ Spectinomycin is now seldom used due to the high cost and practical unavailability but remains useful in special instances, such as treating pregnant women with severe penicillin allergy or cephalosporin-resistant gonorrhoea. In most countries, quinolones rather than intramuscular ceftriaxone replaced penicillins and spectinomycin as first-line oral therapy for gonorrhoea in the 1980s and were used with success for over a decade before resistance developed, initially in the Asia Pacific region and subsequently in the USA, Europe and Africa. ${ }^{13}$

\section{Modern treatment of gonorrhoea}

With the demise of quinolones, physicians treating gonorrhoea turned to the last remaining class of effective antigonococcal antibiotics, namely cephalosporins. Oral third generation cephalosporins, such as cefixime and cefpodoxime, are still being used with success as single-dose oral agents in many countries. Reports of gonococci exhibiting decreased susceptibility and resistance to oral cephalosporins have been seen in Japan since 2001, and more recently in other countries in the western Pacific region and Europe. ${ }^{4-7}$ Although the genetic basis of resistance to oral cephalosporins has yet to be fully elucidated, the presence of a mosaic penA gene appears to be the predominant mechanism. ${ }^{1}{ }_{8}$ At present, intramuscular ceftriaxone is the only antibiotic that still offers reliable cure for genital gonorrhoea, and it is likely to continue to do so unless the gonococcus acquires the ability to express an extended spectrum $\beta$-lactamase. Such an event is viewed with trepidation, as it will herald an era of extensively drug-resistant gonorrhoea and, unless new therapeutic agents are made available, gonorrhoea may potentially become untreatable.

\section{Methods of detecting drug-resistant gonorrhoea}

The traditional method of antimicrobial susceptibility testing relies on the presence of viable $N$ gonorrhoeae isolates, which can be tested using disc diffusion or minimum inhibitory concentration assays using either Etest or agar dilution methodologies. Molecular assays for the detection of key antibiotic resistance genetic mutations or resistance-encoding plasmids have been described but are not yet in routine clinical use. ${ }^{9} 10$ Although molecular techniques offer enormous potential for the diagnosis of gonorrhoea, their use in antimicrobial susceptibility testing has several limitations. First, such an approach is not practical for those antibiotics for which several different resistance mechanisms exist and, second, molecular resistance assays will not detect new mechanisms of resistance for which phenotypic culture-based assays are required.

\section{Surveillance systems for monitoring the prevalence of antimicrobial-resistant $\boldsymbol{N}$ gonorrhoeae}

One key challenge to effective gonococcal control in the current era of multidrug-resistant gonorrhoea is that few countries have effective gonococcal sentinel surveillance programmes in place. The 
Table 1 Non-microbiological determinants that directly contribute to antimicrobial resistance

\begin{tabular}{ll}
\hline $\begin{array}{l}\text { Non-microbiological determinants directly contributing to antimicrobial } \\
\text { resistance }\end{array}$ & Prescribed use of inappropriate drugs and doses \\
\hline Drug prescribing, quality and & Variable quality of generic antimicrobial agents \\
access & Lack of access to efficacious antimicrobial \\
& agents (stock-outs) \\
Consumer and provider health & Lack of information dissemination and training \\
education & regarding antimicrobial resistance (clinical staff, \\
& general public) \\
& Readily available non-clinical access to \\
& antimicrobial agents (pharmacies, traditional \\
& healers, self-prescribing) \\
Importation of antimicrobial & Lack of adherence to the prescribed course of \\
resistant strains & antimicrobial agents \\
\hline
\end{tabular}

problem is being compounded due to the replacement of traditional culture and susceptibility testing with nucleic acid amplification tests as the diagnostic method of choice in highincome countries and the practice of treating patients with suspected gonorrhoea without laboratory testing, as occurs, for example, in those countries using the syndromic management approach.

Examples of sustainable and on-going national programmes include the Gonococcal Isolate Surveillance Project (GISP, 1986-date), coordinated by the US Centers for Disease Control and Prevention, and the Gonococcal Resistance to Antimicrobials Surveillance Programme (GRASP, 2000-date), now coordinated by the UK Health Protection Agency. At a regional level, examples of surveillance networks include the WHO's Western Pacific Region Gonococcal Antimicrobial Surveillance Programme (GASP, 1992-date), the European Surveillance of STI (ESSTI) Programme (2001-date), which is now coordinated by the European Centre for Disease Prevention and Control, and the WHO/Pan-American Health Organisation GASP (1992-date), which formerly involved a network of more than 35 countries in Latin America and the Caribbean. In an attempt to provide an up-to-date global picture of gonococcal resistance, the WHO is currently supporting, renewing and initiating additional GASP activities in South East Asia, Africa, Latin America and eastern Europe. ${ }^{5} 11$ In a similar manner to the national and regional surveillance programmes mentioned above, the WHO's GASP initiative is supported by surveillance protocols, definitions for multidrug-resistant and extensively drug-resistant $N$ gonorrhoeae and a new panel of control gonococcal strains appropriate for the global antibiotic resistance patterns now observed. ${ }^{5} 12$

\section{Potential treatment strategies in an era of multidrug-resistant gonorrhoea}

In terms of the treatment of gonorrhoea resistant to oral cephalosporins, single-dose intramuscular ceftriaxone $250 \mathrm{mg}$ still remains effective. Single-dose intramuscular spectinomycin $2 \mathrm{~g}$ and oral azithromycin $2 \mathrm{~g}$ are alternative second-line agents, although neither should be used as first-line agents due to the ease with which gonococci may develop resistance to these two antibiotics. Several strategies, which have yet to be evaluated in clinical trials, have been proposed to prolong the usefulness of current effective antibiotics, including higher cephalosporin doses, multidose cephalosporin regimens, multidrug regimens, microbiologically directed treatment and, should an alternative effective first-line antibiotic become available, drug cycling. ${ }^{13}$
Engagement with research funders and the pharmaceutical industry is urgently required in order to highlight the need for new therapeutic agents to treat $N$ gonorrhoeae infections in the future.

\section{T PALLIDUM INFECTION}

\section{Syphilis treatment in the pre-antibiotic era}

Several potentially toxic treatments, including mercury salves and inunctions, and arsenic and bismuth compounds, were used in the pre-antibiotic era to ward off the possibility of very serious, sometimes fatal, late manifestations of syphilis. The discovery and introduction of penicillin in the 1940s revolutionised the treatment of syphilis, providing for the first time a safe and highly effective remedy.

\section{Penicillin-based treatment for syphilis}

The causative agent of syphilis, $T$ pallidum, divides very slowly, and treponemacidal levels of penicillin must be maintained for approximately 10-14 days to cure early syphilis, or up to 30 days for late syphilis. A single dose of the currently recommended benzathine penicillin G (BPG) provides effective levels of penicillin for at least 2-3 weeks, thus making single-dose therapy possible for early syphilis. Unfortunately, BPG has minimal ability to cross the blood-brain barrier and viable $T$ pallidum, as well as $T$ pallidum DNA, have been detected in the cerebrospinal fluid (CSF) of infected persons following BPG treatment. ${ }^{14} 15$ The possible presence of viable treponemes in CSF following treatment is of concern, particularly in HIVinfected individuals. Although serological and microbiological treatment failures have been reported following BPG treatment, these may be due to sequestration of treponemes protected in the central nervous system or to re-infection. There has been no documented case of penicillin-resistant $T$ pallidum.

\section{Alternative antibiotic therapies for syphilis}

For persons who are allergic to penicillin, the tetracyclines (eg, tetracycline and doxycycline), macrolides (eg, erythromycin, and more recently, azithromycin), chloramphenicol, and thirdgeneration cephalosporins (eg, ceftriaxone) have been used and, except for chloramphenicol, are recommended by international experts. Higher failure rates have been seen with tetracycline and erythromycin, compared with BPG, but it is unclear whether these failures were due to biological causes or to lack of compliance with the more complicated dosing schedule for the oral drugs. The efficacy, safety and ease of use of azithromycin made it appropriate to use partner-delivered therapy approaches to control syphilis outbreaks in defined populations; this approach was implemented in men who have sex with men in San Francisco beginning in 1999-2000. However, in 2002, the first of several cases of clinical failure following azithromycin treatment for syphilis was identified in San Francisco. ${ }^{16}$

\section{Recognition of $T$ pallidum macrolide resistance}

Historically, a single strain of erythromycin-resistant $T$ pallidum (called Street Strain 14) was isolated by John Clark at the US Centers for Disease Control and Prevention from a man who had failed intensive erythromycin treatment for secondary syphilis. Stamm and Bergen ${ }^{17}$ subsequently demonstrated that this resistance was associated with an $\mathrm{A} \rightarrow \mathrm{G}$ transition in both copies of the $23 \mathrm{~S}$ rRNA gene in this strain. Following the appearance of azithromycin treatment failures in San Francisco, laboratory analysis of swab samples from syphilis-infected patients showed 
Table 2 Mechanisms of antibiotic resistance and recommendations for treatment of $N$ gonorrhoeae

\begin{tabular}{|c|c|c|}
\hline Antimicrobial agent or class & $\begin{array}{l}\text { Described mechanisms } \\
\text { of resistance }\end{array}$ & $\begin{array}{l}\text { Recommendations } \\
\text { for current use }\end{array}$ \\
\hline Sulphonamides & $\begin{array}{l}\text { Over-synthesis of p-aminobenzoic acid } \\
\text { Chromosomal mutations in the dihydropteroate synthetase gene } \\
\text { No recorded plasmid-mediated resistance }\end{array}$ & Not recommended \\
\hline Thiamphenicol & $\begin{array}{l}\text { Chromosomal mutations in the pen } B, m t r R \text { and } c h l \text { genes } \\
\text { No recorded plasmid-mediated resistance }\end{array}$ & Not recommended \\
\hline Penicillins & $\begin{array}{l}\text { Chromosomal mutations in the penA, penB, } \\
\text { ponA, mtrR promoter and } m \text { trR genes } \\
\text { Chromosomal mutation in the penC (pilO2) } \\
\text { gene has been described in the laboratory } \\
\text { but the mutation affects pilus formation and } \\
\text { is thus of doubtful significance in terms of } \\
\text { naturally acquired infection } \\
\text { Altered expression of the pem gene } \\
\text { Plasmid-mediated production of } \beta \text {-lactamase }\end{array}$ & $\begin{array}{l}\text { Recommended only in areas where data from regular } \\
\text { on-going local surveillance programmes confirm that } \\
\text { over } 95 \% \text { of clinical isolates are susceptible to } \\
\text { penicillins }\end{array}$ \\
\hline Tetracyclines & $\begin{array}{l}\text { Chromosomal mutations in the rpsJ, penB, mtrR } \\
\text { promoter and mtrR genes } \\
\text { Chromosomal mutation in the penC (pilO2) gene } \\
\text { has been described in the laboratory but the } \\
\text { mutation affects pilus formation and is thus of } \\
\text { doubtful significance in terms of naturally } \\
\text { acquired infection } \\
\text { Altered expression of the tem gene } \\
\text { Plasmid-mediated production of the TetM protein }\end{array}$ & Not recommended \\
\hline Spectinomycin & $\begin{array}{l}\text { - Chromosomal mutations in the } s p c \text { gene } \\
\text { - No recorded plasmid-mediated resistance }\end{array}$ & $\begin{array}{l}\text { Not recommended as a first-line agent due to } \\
\text { the ease with which resistance may occur } \\
\text { Recommended as a second or third-line agent }\end{array}$ \\
\hline Aminoglycosides & $\begin{array}{l}\text { Chromosomal mutations in the kan gene } \\
\text { No recorded plasmid-mediated resistance }\end{array}$ & $\begin{array}{l}\text { Generally not recommended as first-line agents, } \\
\text { although kanamycin and gentamicin are still used } \\
\text { as such in certain resource-poor countries } \\
\text { May be used as a second or third-line agent }\end{array}$ \\
\hline Macrolides & $\begin{array}{l}\text { Chromosomal mutations in the 23sRNA } r r l \text {, the } \\
m t r R / m t r C \text { promoter, mtrR and } m \text { trC genes } \\
\text { Chromosomal expression of ermB, ermC and ermF } \\
\text { methylase-encoding genes } \\
\text { Role of the chromosomally encoded mef gene is of } \\
\text { uncertain significance } \\
\text { No recorded plasmid-mediated resistance }\end{array}$ & $\begin{array}{l}\text { Azithromycin is not recommended as a first-line } \\
\text { agent due to the ease with which resistance } \\
\text { may occur } \\
\text { Azithromycin recommended as a second or } \\
\text { third-line agent } \\
\text { Other macrolides are not recommended }\end{array}$ \\
\hline Quinolones & $\begin{array}{l}\text { Chromosomal mutations in the gyrA and parC genes } \\
\text { No recorded plasmid-mediated resistance }\end{array}$ & $\begin{array}{l}\text { Recommended only in areas where data from } \\
\text { regular on-going local surveillance programmes } \\
\text { confirm that over } 95 \% \text { of clinical isolates are } \\
\text { susceptible to quinolones }\end{array}$ \\
\hline Cephalosporins & $\begin{array}{l}\text { Chromosomal mosaic penA genes } \\
\text { Chromosomal mutations in the pen } A \text {, pen } B \text {, pon } A \text {, } \\
m t r R \text { promoter and } m t r R \text { genes } \\
\text { No recorded plasmid-mediated resistance }\end{array}$ & $\begin{array}{l}\text { Recommended as first-line agents, either } \\
\text { intramuscularly (ceftriaxone) or orally (eg, cefixime, } \\
\text { cefpodoxime, ceftibuten depending on local availability) } \\
\text { In areas where gonococcal strains are circulating } \\
\text { with decreased susceptibility to oral cephalosporins, } \\
\text { intramuscular ceftriaxone should be used at higher } \\
\text { doses }(500 \mathrm{mg}-1 \mathrm{~g})\end{array}$ \\
\hline
\end{tabular}

This table has been modified from a version previously published in Sexually Transmitted Infections by one of the authors (DAL). ${ }^{1}$

the presence of an A2058G mutation in the 23S rRNA gene of some circulating $T$ pallidum strains, identical to that identified in the Street Strain 14. Molecular analysis of isolated historical strains and swab samples collected from a variety of geographical sites (including San Francisco, Seattle, Baltimore and Dublin) revealed identical mutations in a subset of samples. ${ }^{18}$ Importantly, the proportion of samples containing this mutation has increased over time in both San Francisco and Seattle, with recent levels greater than $80 \%$ in men who have sex with men.

Following these reports, A2058G mutations in $T$ pallidum were reported from Vancouver and Alberta, Canada, as well as Shanghai, China. Zhou et al ${ }^{19}$ reported the failure of azithromycin treatment of pregnant women to prevent congenital syphilis in five infants born in Shanghai between 1998 and 2004, but it is unclear whether this failure occurred because of the poor penetration of the placenta by the drug or because of the unrecognised presence of macrolide-resistant $T$ pallidum strains at that time. Matějková and colleagues ${ }^{20}$ recently described a clinical failure of spiramycin, another macrolide antibiotic used for the treatment of syphilis in the Czech Republic, in a patient with secondary syphilis. This strain contained a different mutation (A2059G), which was also identified in additional samples collected from 2005 to 2008.

The origin of strains with macrolide resistance mutations is unknown. Several possible theories exist, including the unrecognised existence of such strains for many years, with selection due to the widespread use of azithromycin for the treatment of Chlamydia trachomatis or for prophylaxis of Mycobacterium avium complex, and the real-time selection of spontaneous mutants by antibiotic pressure. Marra and coworkers ${ }^{21}$ demonstrated that $T$ pallidum strains containing the A2058G mutation were more likely to be found in persons who had taken macrolide antibiotics in the preceding year; importantly, strains containing the resistance mutation can be divided into multiple molecular types, indicating that the mutation is not restricted to a single strain type, even within a city.

\section{Global challenges in the detection of resistance mutations in $T$ pallidum}

The identified macrolide resistance mutations can be identified in strains by restriction digestion of PCR products. ${ }^{18}$ Because these techniques are available in only a limited number of 
Table 3 Mechanisms of antibiotic resistance and recommendations for treatment of $T$ pallidum

\begin{tabular}{|c|c|c|}
\hline $\begin{array}{l}\text { Antimicrobial } \\
\text { agent or class }\end{array}$ & $\begin{array}{l}\text { Described mechanisms } \\
\text { of resistance }\end{array}$ & Recommendations for current use \\
\hline Penicillins & $\begin{array}{l}\text { No penicillin resistance } \\
\text { documented in } T \text { pallidum }\end{array}$ & $\begin{array}{l}\text { Benzathine penicillin } G \text { is recommended for all stages of syphilis, except neurosyphilis } \\
\text { For symptomatic or asymptomatic neurosyphilis, aqueous crystalline penicillin } G \text { or aqueous procaine } \\
\text { penicillin } G+\text { probenecid are recommended } \\
\text { When possible, penicillin desensitisation is the preferred option for treating penicillin allergic patients who are } \\
\text { pregnant or have neurosyphilis }\end{array}$ \\
\hline Tetracyclines & $\begin{array}{l}\text { No tetracycline resistance } \\
\text { documented in } T \text { pallidum }\end{array}$ & $\begin{array}{l}\text { Doxycycline and tetracycline are recommended for persons with penicillin allergy, except during } \\
\text { pregnancy. Compliance may be problematical, and penicillin is preferred if possible }\end{array}$ \\
\hline Macrolides & $\begin{array}{l}\text { Chromosomal point mutations } \\
\text { in the 23sRNA genes } \\
\text { (A2058G and A2059G) }\end{array}$ & $\begin{array}{l}\text { Macrolides, including azithromycin and erythromycin (which was formerly recommended as an alternative } \\
\text { for penicillin allergic persons) should be used only when penicillin or tetracyclines cannot be used. } \\
\text { Macrolides should be used with caution unless the prevalence of resistance in locally circulating strains of } T \\
\text { pallidum is known to be very low. If macrolides are used, careful follow-up must be assured. Infected infants } \\
\text { have been born to pregnant women treated with macrolides during pregnancy, due to poor penetration of this } \\
\text { class of drugs to the fetus. With the increasing prevalence of macrolide-resistant strains of } T \text { pallidum, the } \\
\text { risk of macrolide treatment failure is further heightened }\end{array}$ \\
\hline Cephalosporins & $\begin{array}{l}\text { No cephalosporin resistance } \\
\text { documented in } T \text { pallidum }\end{array}$ & $\begin{array}{l}\text { Limited clinical experience and pharmacokinetics data suggest that ceftriaxone should be effective for all stages } \\
\text { of syphilis, although optimal dose and duration have not been determined. Penicillin allergy may crossreact with } \\
\text { ceftriaxone in some individuals }\end{array}$ \\
\hline
\end{tabular}

laboratories, samples from most geographical regions cannot readily be tested. There is a need for an international surveillance programme to determine the current geographical distribution of resistant strains and to assess the prevalence of resistant strains in many geographical areas periodically. This could be achieved most economically at a regional reference laboratory level using DNA extracts from ulcer swabs found to be positive for $T$ pallidum by molecular testing. A global surveillance programme would require the establishment of a network of laboratories with expertise in molecular testing and sequencing of $T$ pallidum, commitment by countries to send appropriate samples and adequate funding to support the network and testing. Published successful azithromycin treatment trials from Africa have led to the naive belief that resistant strains may not be present on that continent. ${ }^{22-24}$ It is important to recognise that these trials were conducted in 1994-7, 2000-3 and 2000-7, either before or very early in the recognition of such resistant strains elsewhere. There are no recent data on macrolide resistance from Africa.

\section{Recommendations for syphilis treatment in light of the emergence of resistance}

Penicillin $G$ remains the preferred treatment for syphilis of all stages. Doxycycline or tetracycline should be considered as second-line drugs for uncomplicated syphilis, to be used when penicillin treatment is not possible (table 3). Macrolides, including azithromycin, should be used only in regions where the prevalence of resistant strains is known to be low, and treated patients require close follow-up.

\section{CONCLUSIONS}

As antimicrobial resistance increases on a global scale, treatments for gonorrhoea and syphilis need to be tailored to ensure that over $95 \%$ of clinical infections respond to first-line treatment regimens in accordance with WHO recommendations. This can be achieved only by the determination of antibiotic susceptibility phenotypes or genotypes for these pathogens through national and regional surveillance activities. For most of the world, such activities are weak or non-existent. Globally, surveillance efforts require significant strengthening through capacity building of laboratories, enhanced sharing of information between surveillance units, and the provision of sustainable funding from both governments and donor agencies. Finally, there is a need to prioritise funding for research into new therapeutic agents for STI pathogens, particularly in the case of $N$ gonorrhoeae, before existing treatment options disappear.

Acknowledgements Due to editorial constraints, the authors were unable to reference all of the relevant publications related to this topic.

Competing interests DAL is a member of the Merck Serono Advisory Board for the planned launch of Fixime (cefixime) within South Africa in 2011. SAL has no competing interests.

Contributors Both authors co-wrote and revised the paper.

Provenance and peer review Commissioned; externally peer reviewed.

\section{REFERENCES}

1. Lewis DA. The Gonococcus fights back: is this time a knock out? Sex Transm Infect 2010:86:415-21.

2. Boslego JW, Tramont EC, Takafuji ET, et al. Effect of spectinomycin use on the prevalence of spectinomycin-resistant and of penicillinase-producing Neisseria gonorrhoeae. N Engl J Med 1987;317:272-8.

3. Dan $\mathbf{M}$. The use of fluoroquinolones in gonorrhoea: the increasing problem of resistance. Expert Opin Pharmacother 2004;5:829-54.

4. Ito $\mathbf{M}$, Yasuda M, Yokoi S, et al. Remarkable increase in central Japan in 2001-2002 of Neisseria gonorrhoeae isolates with decreased susceptibility to penicillin, tetracycline, oral cephalosporins, and fluoroquinolones. Antimicrob Agents Chemother 2004:48:3185-7.

5. Tapsall JW, Ndowa F, Lewis DA, et al. Meeting the public health challenge of multidrug- and extensively drug-resistant Neisseria gonorrhoeae. Expert Rev Anti Infect Ther 2009; 7:821-34.

6. Ison C, Hussey J, Sankar K, et al. Gonorrhoea treatment failures to cefixime and azithromycin in England, 2010. Euro Surveill 2011;16:pii=19833.

7. Unemo M, Golparian D, Syversen G, et al. Two cases of verified clinical failures using internationally recommended first-line cefixime for gonorrhoea treatment, Norway, 2010. Euro Surveill 2010;15:pii=19721.

8. Ito M, Deguchi T, Mizutani KS, et al. Emergence and spread of Neisseria gonorrhoeae clinical isolates harboring mosaic-like structure of penicillin-binding protein 2 in Central Japan. Antimicrob Agents Chemother 2005;49:137-43.

9. Kugelman G, Tapsall JW, Goire N, et al. Simple, rapid, and inexpensive detection of Neisseria gonorrhoeae resistance mechanisms using heat-denatured isolates and SYBR green-based real-time PCR. Antimicrob Agents Chemother 2009;53:4211-16.

10. Fayemiwo SA, Muller EE, Gumede L, et al. Plasmid-mediated penicillin and tetracycline resistance among Neisseria gonorrhoeae isolates in South Africa: prevalence, detection and typing using a novel molecular assay. Sex Transm Dis 2011;38:329-33.

11. Tapsall JW, Limnios EA, Abu Bakar HM, et al. Surveillance of antibiotic resistance in Neisseria gonorrhoeae in the WHO Western Pacific and South East Asian regions, 2007-2008. Commun Dis Intell 2010;34:1-7.

12. Unemo M, Fasth 0 , Fredlund $\mathrm{H}$, et al. Phenotypic and genetic characterization of the 2008 WHO Neisseria gonorrhoeae reference strain panel intended for global quality assurance and quality control of gonococcal antimicrobial resistance surveillance for public health purposes. J Antimicrob Chemother 2009;63:1142-51.

13. Chisholm SA, Mouton JW, Lewis DA, et al. Cephalosporin MIC creep among gonococci: time for a pharmacodynamic rethink? J Antimicrob Chemother 2010;65:2141-8.

14. Lukehart SA, Hook EW 3rd, Baker-Zander SA, et al. Invasion of the central nervous system by Treponema pallidum: implications for diagnosis and treatment. Ann Intern Med 1988;109:855-62. 
15. Rolfs RT, Joesoef MR, Hendershot EF, et al. A randomized trial of enhanced therapy for early syphilis in patients with and without human immunodeficiency virus infection. The Syphilis and HIV Study Group. N Engl J Med 1997:337:307-14.

16. Mitchell SJ, Engelman J, Kent CK, et al. Azithromycin-resistant syphilis infection: San Francisco, California, 2000-2004. Clin Infect Dis 2006; 42:337-45.

17. Stamm LV, Bergen HL. A point mutation associated with bacterial macrolide resistance is present in both 23S rRNA genes of an erythromycin-resistant Treponema pallidum clinical isolate. Antimicrob Agents Chemother 2000:44:806-7.

18. Lukehart SA, Godornes C, Molini BJ, et al. Macrolide resistance in Treponema pallidum in the United States and Ireland. N Engl J Med 2004;351:154-8.

19. Zhou $\mathbf{P}$, Qian $\mathbf{Y}, \mathbf{X u} \mathrm{J}$, et al. Occurrence of congenital syphilis after maternal treatment with azithromycin during pregnancy. Sex Transm Dis 2007;34:472-4.
20. Matejkova $\mathbf{P}$, Flasarova $\mathrm{M}$, Zakoucka $\mathrm{H}$, et al. Macrolide treatment failure in a case of secondary syphilis: a novel A2059G mutation in the 23S rRNA gene of Treponema pallidum subsp. pallidum. J Med Microbiol 2009;58:832-6.

21. Marra CM, Colina AP, Godornes C, et al. Antibiotic selection may contribute to increases in macrolide-resistant Treponema pallidum. J Infect Dis 2006;194:1771-3.

22. Hook EW 3rd, Behets F, Van Damme K, et al. A phase III equivalence trial of azithromycin versus benzathine penicillin for treatment of early syphilis. J Infect Dis 2010;201:1729-35

23. Kiddugavu MG, Kiwanuka N, Wawer MJ, et al. Effectiveness of syphilis treatment using azithromycin and/or benzathine penicillin in Rakai, Uganda. Sex Transm Dis 2005;32:1-6.

24. Riedner G, Rusizoka M, Todd J, et al. Single-dose azithromycin versus penicillin $G$ benzathine for the treatment of early syphilis. N Engl J Med 2005;353:1236-44. 